\title{
A Study of Displacement-based Aseismic Design of Building Structure
}

\author{
Cao BaoShan ${ }^{1, a}$ \\ ${ }^{1}$ Chongqing College of Electronic Engineering, Chongqing, 401331, China \\ acbssx@163.com
}

Keywords: displacement-based; building structure; aseismic design; method

\begin{abstract}
With the frequent occurrence of earthquake disaster, the aseismic design of building structure has attracted more attention, especially the displacement-based aseismic design of building structure has been widely applied into practice. This thesis begins with the three methods of displacement-based aseismic design, that is, Ductility Coefficient Method, Capacity Spectrum Method and Directly Displacement-based Design Method. Moreover, the related applications have been studied as well. It not only has certain guiding significance for the development of engineering structure design, but also improve the aseismic capability of building structure in a certain extent, which has great practical significance.
\end{abstract}

\section{Introduction}

In recent years, the earthquake disaster has occurred frequently, which has brought the people with huge life and property damage. For instance, 8 magnitude earthquake in Wenchuan, 7.3 magnitude earthquake in Haiti and other earthquake disaster have caused severe damage to many buildings. Through researching relevant theories and experiments, it is found the main reason leading to building structure collapse is that the deformation capacity and energy dissipation capacity are insufficient, which also reflects the importance of displacement-based aseismic design of building structure from the side, and can effectively control the behavior of building structure to a certain extent. Under such environment trend, the displacement-based aseismic design method of building structure has attracted great attention of the public. In the early 1960s, however, the Displacement Based Design (DBD) has been proposed, and it has achieved good results during the process of continuous research, which can ensure that the structure and components are designed through the displacement response of structures under the earthquake with a certain-level, so as to meet the predetermined performance requirements.

\section{The advantages of displacement-based aseismic design}

When conducting the aseismic design of building structure, the main criteria is based on performance, namely based on cost-effectiveness criterion, combining the commonness and individuality of structural aseismic design, so as to design economical and reliable multi-function building structure to meet the requirements of the owners and fortification goal requirement. Under different performances, however, the most prominent and common one is the displacement-based aseismic design of building structures. It is necessary to determine the corresponding target lateral curve according to the performance requirements of the structure, so as to calculate the base shear force of the structure and the horizontal earthquake action and its effect of each particle, on the basis of which to calculate the section bearing capacity of the components; it also needs to ensure the structure to achieve the expected performance level through designing the deformation capacity of component section according to the deformation demands of structures under the earthquake intensity with certain level. Its advantages are shown as below:

(1) The design of the structure is based on the target displacement, so that there is a certain understanding of the deformation state of the structure when in damage;

(2) Linear system can be used to replace the original structure. In the elastic case, the design method of the component can be directly introduced without considering the nonlinear properties of the structure; 
(3) According to different functional requirements, the stiffness and strength of the structure are designed under different displacement conditions, so as to meet the needs of multi-level earthquake resistance;

(4) A large number of earthquake damage shows that the structural damage is not determined by internal force sometimes, but by acceleration and deformation; at the same time, although the structure does not fall in huge earthquake, it may still suffer normal usage function damage or even serious economic losses. That is to say, the current bearing capacity-based aseismic design method exists some disadvantages, while the displacement-based aseismic design method can solve these problems.

(5) The traditional design process is to assume the section in advance, and then check its aseismic performance. However, displacement-based method can directly obtain the section parameters required by structural aseismic requirements.

\section{Displacement-based aseismic design method of building structure}

At present, the most widely used displacement-based aseismic design of building structure mainly has 3 methods, which are Ductility Coefficient Method, Capacity Spectrum Method and Direct Displacement-based Design Method. All of these three methods have to determine the interlayer displacement angle requirements of the frame under huge earthquake actions as well as the relationship between frame interlayer displacement and component deformation under the elastic-plastic state, so as to truly achieve the design of component deformation capacity through the aseismic structural measures.

\section{Aseismic design of Capacity Spectrum Method}

Capacity Spectrum Method is widely noted in displacement-based, aseismic design method of building structure. Japan Building Standards Law and the U.S. ATC adopt Capacity Spectrum Method as the analysis method of displacement-based aseismic design. The specific implementation steps are shown as below:

First of all, the plastic deformation mechanism, which is accepted selection structure system, is designed under the guidance of current structural aseismic design code, especially the plastic hinge region and the section which can ensure to have no brittle failure, which should be meticulously conducted the structural design, so as to realize the stated goal. Secondly, for the loading mode of the structure, the horizontal force that has a monotonically increasing distribution should be added, and the original structure should be replaced by two-dimensional or three-dimensional mathematical models. According to the predetermined loading mode of horizontal load, "push" the structure to a given target displacement and calculate the relation curve of base share force $\mathrm{V}_{\mathrm{b}}$ of the structure and top displacement $U_{n}$ (as shown in Figure1). It aims to analyze the response when entering into nonlinear state, so as to determine whether the deformation force of structure and component can meet the requirements of design as well as the stated goal of use function.

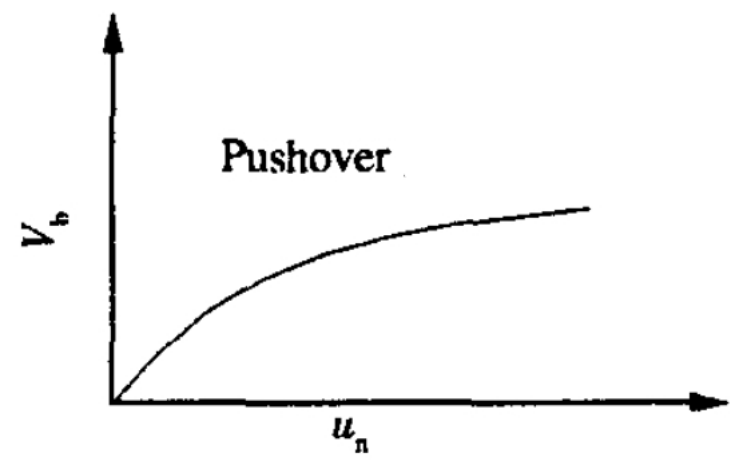

Figure $1 \mathrm{~V}_{\mathrm{b}}-\mathrm{u}_{\mathrm{n}}$ relation curve

For building structure with different height, the structure aseismic effect of high vibration mode should use the loading mode of nonlinearity horizontal force, namely: 


$$
\begin{gathered}
F_{\mathrm{i}}=\frac{\omega_{\mathrm{i}} \mathrm{h}_{\mathrm{i}}{ }^{\mathrm{k}}}{\sum_{\mathrm{j}=1}^{\mathrm{n}} \omega_{\mathrm{j}} \mathrm{h}_{\mathrm{j}}{ }^{\mathrm{k}}} V_{\mathrm{b}} \quad \\
\mathrm{k}=\left\{\begin{array}{cc}
1.0 & T \leq 0.5 \mathrm{~s} \\
1.0+\frac{T-0.5}{2.5-0.5} \ldots 0.5 \mathrm{~s}<T<2.5 \\
2.0 & T \geq 2.5 \mathrm{~s}
\end{array}\right.
\end{gathered}
$$

In formulas mentioned above, $F_{i}$ represents the level loading of the No. $i$ layer; $V_{b}$ is the base shear force; $n$ is the number of layer; $h_{i}$ represents the distance from the No. $i$ layer to the base; $\omega_{\mathrm{i}}$ is the weight of No. i layer; $\mathrm{k}$ means the coefficient related to structural natural period of vibration. Through increasing the level load step by step, we can obtain the rough relationship between the structure base shear force and top displacement.

Once again, use the equivalent unidirection structure to replace original structure. According to the relationship curves of base shear force $V_{b}$ and top displacement $U_{n}$, use formula (3) to convert it into spectral acceleration $S_{a}$. The Capacity Spectrum Curve of spectrum displacement $S_{d}$ (Figure 2).

$$
S_{\mathrm{a}}=\frac{V_{\mathrm{b}}}{M_{1}^{*}}, S_{\mathrm{d}}=\frac{\mathrm{u}_{\mathrm{n}}}{\Gamma_{1}}
$$

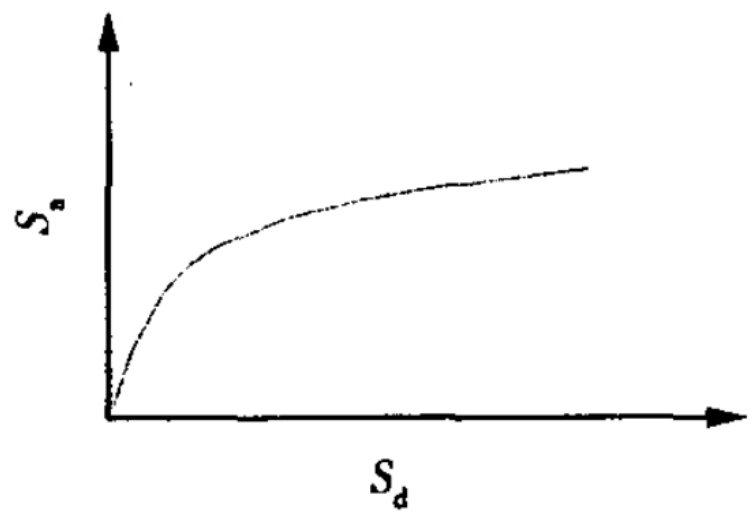

Figure 2. Capacity Spectrum Curve

Finally, on the basis of Chinese Aseismic Design Code, use acceleration response spectrum as the ground motion input of the structure. Moreover, it can be converted into elastic $S_{a}-S_{d}$ spectrum curve based on formula (4). The details are shown as bellow:

$$
S_{\mathrm{d}}=\frac{1}{\omega^{2}} S_{\mathrm{a}}, \quad \omega=\frac{T}{2 \pi}
$$

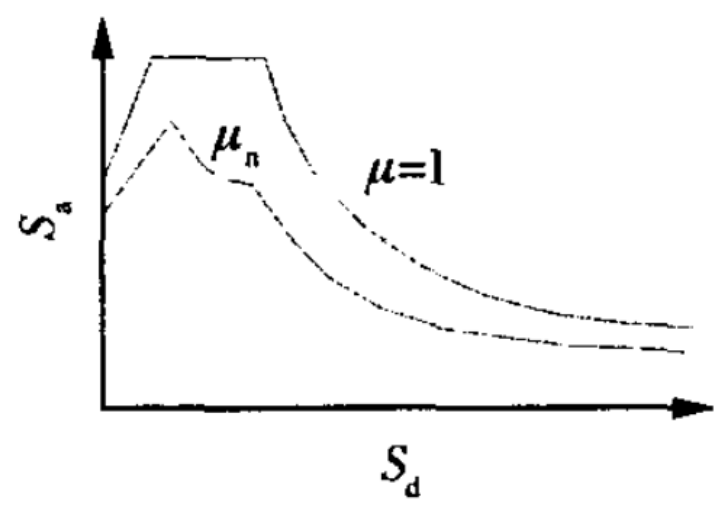

Figure 3. $\mathrm{S}_{\mathrm{a}}-\mathrm{S}_{\mathrm{d}}$ elasticity spectrum curve

After calculating the relevant data, the asynchronous inelastic response spectrum of ductility level is obtained. Then, make the capacity spectrum and earthquake demand spectrum on the same coordinate system, so as to test the aseismic capability of building structure. When the two curves intersect, the displacement of corresponding intersection means the spectrum displacement of equivalent asynchronous system under the earthquake action, that is, demand displacement. If there 
is no intersection, it indicates that the aseismic capacity of the structure is insufficient and need to be redesigned.

\section{Aseismic design of Ductility Coefficient Method}

The so-called Ductility Coefficient Method is also named the Capacity Design Method, whose specific operation practice steps are shown in Figure 4:

Choose energy dissipation mechanisms and energy consumption

building based on structure type and functional level

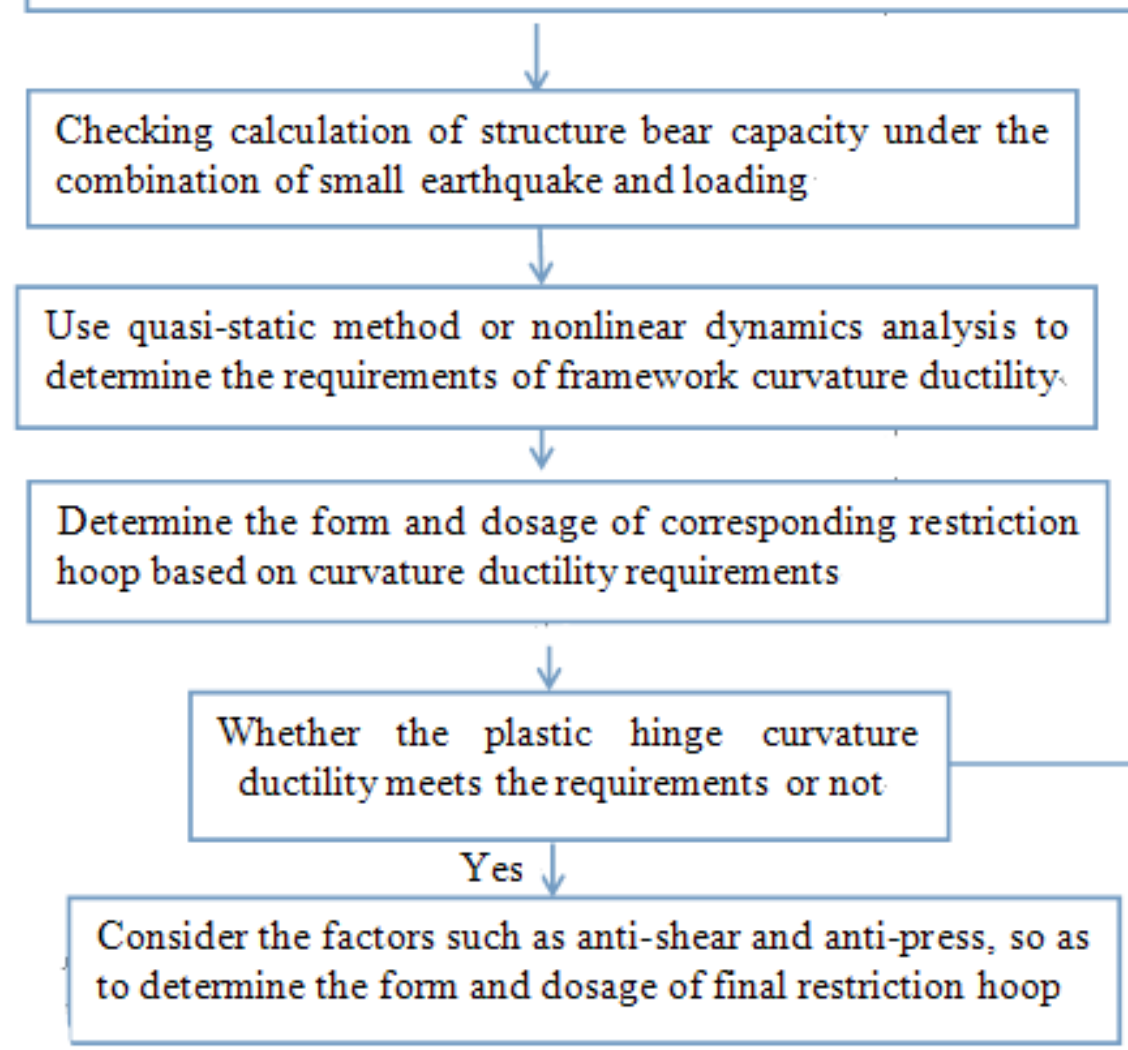

Figure 4. Diagram of aseismic design steps of Ductility Coefficient Method

This method maximally uses ductility demand and the ductility of available utilization. Through comparing their calculations, it is used to evaluate the ductility of the structure, and on this basis, it considers the design of displacement-based ductility structure with torsion effects. Through establishing the relationship between component's displacement ductility coefficient or sectional curvature ductility coefficient and the ultimate compressive strain of plastic hinge concrete, it aims to ensure that the concrete in core area can meet the requirements of ultimate compressive strain with the restriction hoop, so that the components possess the required ductility coefficient.

\section{Aseismic design of Directly Displacement-based Design Method}

Directly Displacement-based Design Method means to directly use displacement as design parameters. For different aseismic fortification levels, the corresponding target displacement is formulated. Moreover, through the design, the structure can reach the pre-specified target displacement under the earthquake action with a given level, so as to realize the control of structural earthquake action. Under the earthquake action, the equation of unidirection structure system motion with inelastic hysteretic behavior equation is shown as below:

$$
\ddot{\mathrm{x}}+2 \zeta_{0} \omega_{0} \dot{\mathrm{x}}+\frac{F(\mathrm{x})}{\mathrm{m}}=-\ddot{\mathrm{x}_{\mathrm{g}}}
$$


In equation (5), $\mathrm{x}$ represents the quality's displacement with respect to the ground; $\mathrm{x}$ means the motion velocity with respect to the ground; $\ddot{x}_{\mathrm{g}}$ means the motion acceleration with respect to the ground; $\mathrm{m}, \zeta_{0}$ and $\omega_{0}$ represent quality, damping ratio and circular frequency of the system respectively. And the calculation formula of circular frequency is shown as below:

$$
\omega_{0}=\sqrt{\frac{\mathrm{k}_{0}}{\mathrm{~m}}}=\frac{2 \pi}{T}
$$

Where, $\mathrm{K}_{0}$ and $\mathrm{T}$ refer to stiffness and cycle of the system. In inelastic structure, the equivalent elastic structure, which has approximate smaller stiffness (equivalent stiffness) and larger damping ratio (equivalent damping ratio), is mostly used to replace the corresponding non-elastic structure for analysis. The formula of equivalent elastic structure system is shown as below:

$$
\ddot{\mathrm{x}}+2 \zeta_{\mathrm{cff}} \omega_{\text {cff }}+\dot{\mathrm{x}}+\omega_{\mathrm{cff}}^{2} \mathrm{x}=-\ddot{\mathrm{x}}_{\mathrm{g}}
$$

Under the earthquake action, assuming that the equivalent elastic structure with a viscous damping ratio consumes the same energy as the initial elastic-plastic structure, then, the specific viscous damping ratio is considered to be the equivalent damping ratio of equivalent elastic structure. According to equivalent energy dissipation criterion, combined with hysteresis model, the relationship between equivalent damping ratio and structure ductility demand can be deduced as below:

$$
\zeta_{\mathrm{cq}}=\zeta_{0}+\frac{1}{\pi}\left(1-\frac{1-\mathrm{r}}{\sqrt{\mu}}-\mathrm{r} \sqrt{\mu}\right)
$$

Where, $\zeta_{0}$ refers to the viscous damping ratio of elastic structure; $\mu$ means the displacement ductility coefficient of the system, that is, the ratio of maximum displacement and yield displacement; $r$ is stiffness ratio coefficient, namely, the ratio of tangent stiffness after system yield and initial elastic stiffness. According to target displacement $\Delta_{\mathrm{u}}$, the natural vibration period $T_{\text {cff }}$ of equivalent elastic structure can be found on the elastic displacement spectrum corresponding to equivalent damping ratio $\xi_{\text {cff }}$. Furthermore, the secant stiffness on target displacement $\Delta_{u}$ of equivalent stiffness $K_{\text {cff }}$ corresponding to non-elastic structure can be further determined as well. The details are shown in Figure 5 and Figure 6:

\section{$\Delta$}

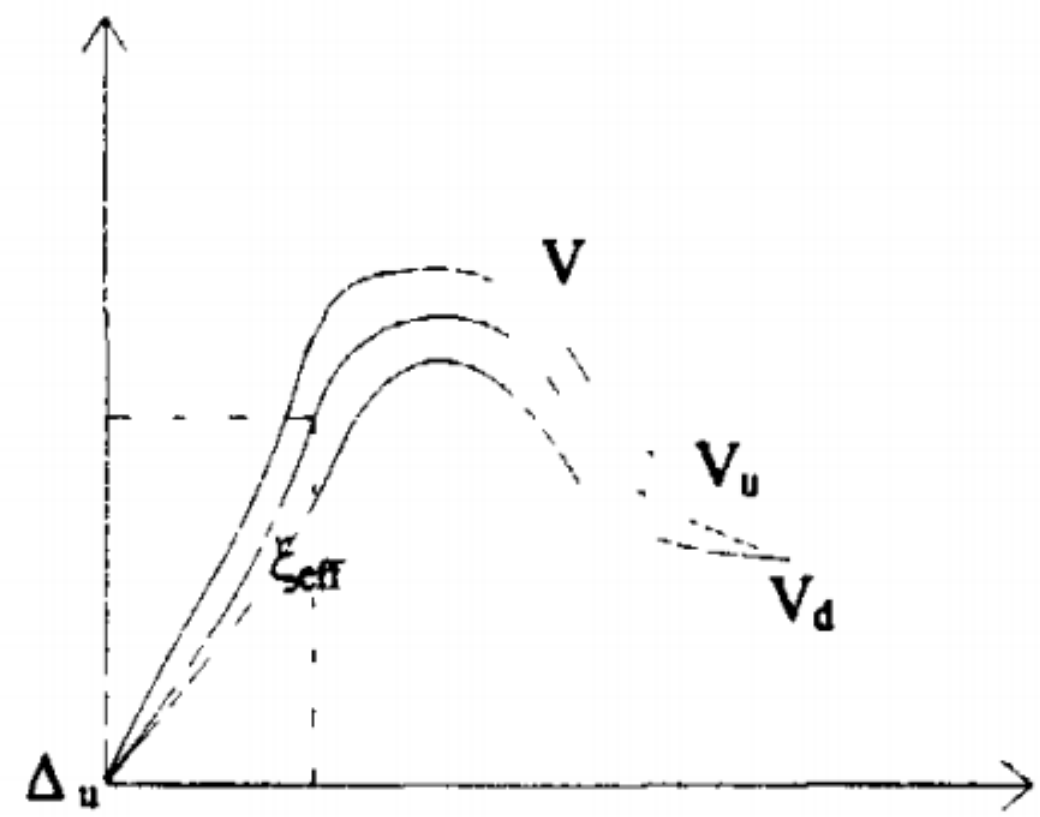

Figure 5. The elastic displacement spectrum of different damping ratio 


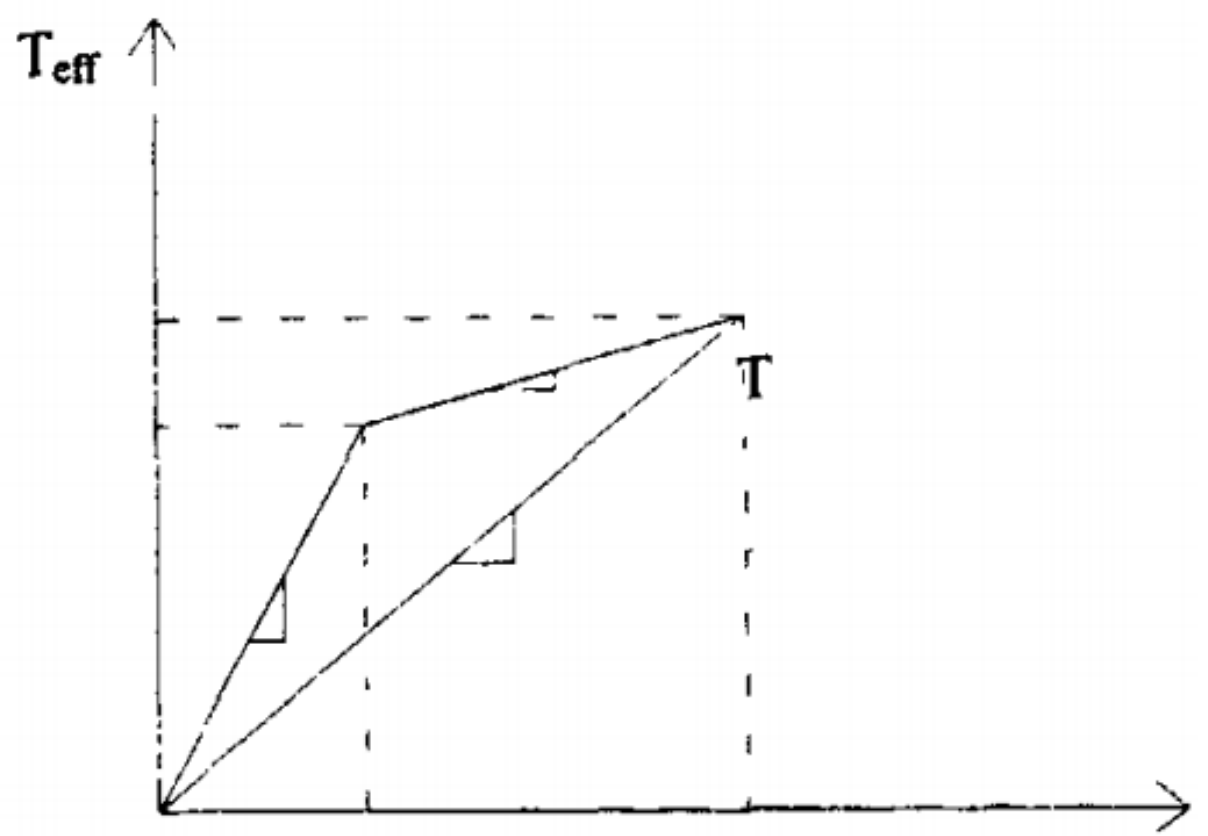

Figure 6. Force of inelastic and equivalent elastic structure---displacement diagram

\section{Conclusion}

In summary, the displacement-based aseismic design of building structure is based on structural aseismic performance analysis, involving all aspects of structural aseismic design, which has great promoting significance for the development of engineering structure design. In order to control the losses of human life and property under the earthquake into the minimum range, the further in-depth studies are still needed. According to the actual situation and the requirements of owners as well as other conditions, it is encouraged to independently choose the structure performance target level, structural measures and the like, so as to meet the different requirements of the structural performance.

\section{Knowledgements}

Project Name1: applicability and experimental study of cooling and evaporative cooling technology in rural areas of Chongqing

Project unit: Science and technology research project of Chongqing Municipal Education Committee

Item number: KJ1602911

Project Name2: data driven predictive control based on subspace identification

Project unit: Science and technology research project of Chongqing Municipal Education Committee

Item number: KJ1503008

\section{Reference}

[1]Li Jian, Zhang Yan. Introduction of Displacement-based Aseismic Design Method of Building Structure[J]. Yinshan Academic Journal: Natural Science Edition, 2010,24(2)32-35.

[2]Li Jian. Displacement-based Aseismic Design Method of Directly High-rise Building Structure[J]. Heilongjiang Science and Technology Information, 2013(10):269.

[3] Ministry of Housing and Urban-Rural Development, People's Republic of China General Administration of Quality Supervision, Inspection and Quarantine. Code for Aseismic Design of Building[M].China Architecture and Building Press, 2010. 
[4]Hu Yuchao. Theory and Method of Aseismic Design of Performance-based Building Structure[J].Jiangxi Building Materials, 2012(4):31-32.

[5]Zhang Jianxin, Li Hui, Li Qingning. Theoretical Development of Aseismic Design of Building Structure[J]. Sichuan Building Science, 2014,40(4):238-241.

[6]Liang Jiongfeng, Wang Jianbao, etc. Displacement-based Aseismic Design of Directly Steel-frame Structure[J]. Sichuan Building Science, 2013,39(3):148-151.

[7]Guo Hua, Jiang Xionghua. A Study of Aseismic Design Method of Modern Building Structure[J].China New Technologies and Products, 2010(16):176. 